\title{
PReS-FINAL-2319: PED-BD cohort 2013: expert consensus classification gives higher sensitivity than the international study group criteria to define Behcet's disease in children
}

\author{
I Koné-Paut ${ }^{*}$, M Darce Bello ${ }^{1}$, F Shahram² ${ }^{2}$ S Ozen ${ }^{3}$, R Cimaz $^{4}$, H Michael $^{5}$, M Gattorno $^{6}$, B Chkirate $^{7}$, K Bouayed $^{8}$, \\ L Cantarini ${ }^{9}$, J Anton ${ }^{10}$, I Tugal-Tuktun ${ }^{11}$, J Kummerle-Deschner ${ }^{12}$, A Faye ${ }^{13}$, S Benamour ${ }^{14}$, TA Tran ${ }^{1}$, A Arnoux ${ }^{15}$, \\ PED-BD
}

From 20th Pediatric Rheumatology European Society (PReS) Congress Ljubljana, Slovenia. 25-29 September 2013

\section{Introduction}

$\mathrm{BD}$ is rarely encountered in children where the disease is very difficult to recognize. The outcome ofpatients with few symptoms is currently unknown

\section{Objectives}

To define the outcome of paediatric patients with at least two symptoms of $\mathrm{BD}$, and to obtain an appropriate definition of $\mathrm{BD}$ in patients $<16 \mathrm{y}$.

\section{Methods}

An international expert committee has defined the criteria of inclusion. New patients or patients followed for a maximum of 3 years, who presented at least 2 symptoms of BD (among a list), and gave their informed consent were included, reviewed yearly.

\section{Results}

228 patients were included since 2008, (SR: 1 ), from 22 centres of 13 countries, median age of $12.5 \mathrm{y}$. Median age at first symptom was 7.2y. Family history of BD was present in $22 \%$ and consanguinity in $4.5 \%$. Median disease duration at inclusion was $4.7 \mathrm{y}$ and from the first symptom to last visit was $7.5 y$. Inclusion criteria plus oral aphtosis (mandatory) were (\%): genital aphtosis 50, necrotic folliculitis 31 , uveitis 28 , familial history 22, pathergy positive 19 , erythema nodosum 15, vascular 10 and retinal vasculitis 7 .
Mean number of symptoms: 1 plus family history $41 \%, 2$ (33\%), more than 3 (26\%). Patient had a median of $1.3 \mathrm{fol}-$ low-up visit (0-4). 220 patients had a first visit, 138 patients had a 1-y visit (mean BD duration: 5.8y). 81 patients had 2-y (6.4y), 44 a 3-y (7.3y) and 18 a 4-y visit (7.5y). The symptoms along the study were (\%): dermatological 67, genital aphtosis 52, articular 48, fever 47 , gastrointestinal 39 , ocular 36 , neurological 35 , pathergy 17 , vascular 12, urological 2. HLAB51 was present in $47 \%$. Male patients had significantly more ocular and vascular signs, female had more genital aphtosis. Between 1st-4th visit: $57 \%$ had no new symptom, $24 \%$ had $1,11 \%$ had 2 and $10 \%$ had more than 3 . The expert committee has examined 199 files at a median disease duration of $6,1 \mathrm{y}$, and classified 121 patients as definite, 18 as probable and 3 as not BD. 57 charts were reviewed but did not reached consensus. 46 files have been reviewed more than once. Among our patients classified as definite: 121/142 (85\%); $79 / 121$ (65\%) fulfilled the ISG International criteria. International criteria and expert classification showed significant differences. Although good concordance (Kappa c $=$ 0.72 ). Having 2 or more symptoms was significantly associated with classification as definite BD $(\mathrm{p}=0.0005)$.

\section{Conclusion}

The expert committee has classified the majority of patients in the BD group although they did not fulfil the international BD classification criteria (for adults).

${ }^{1}$ Pediatric Rheumatology, Bicêtre University Hospital, Le Kremlin Bicêtre,

France

Full list of author information is available at the end of the article 


\section{Disclosure of interest}

None declared.

\section{Authors' details}

'Pediatric Rheumatology, Bicêtre University Hospital, Le Kremlin Bicêtre, France. ${ }^{2}$ Rheumatology Research, Shariati Hospital, Tehran, Iran, Islamic Republic of. ${ }^{3}$ Pediatric Nephrology, Hacettepe University, Ankara, Turkey. ${ }^{4}$ Pediatric Rheumatology, Meyer Hospital, Florence, Italy. ${ }^{5}$ Pediatric Rheumatology, Vaudois University Hospital, Lausanne, Switzerland. ${ }^{6}$ Pediatric Rheumatology, G. Gaslini, Genoa, Italy. ${ }^{7}$ Pediatrics, Rabat University Hospital, Rabat, Morocco. ${ }^{8}$ Pediatrics, Casablanca University hospital, Casablanca, Morocco. ${ }^{9}$ Medicine and Immunological Sciences, University of Siena, Siena, Italy. ${ }^{10}$ Pediatric Rheumatology, Sant Joan de Déu Hospital, Esplugues de Llobregat, Spain. ${ }^{11}$ Ophtalmology, Istanbul University, Istanbul, Turkey.

${ }^{12}$ Pediatric Rheumatology, University of Tuebingen, Tuebingen, Germany. ${ }^{13}$ Pediatrics, R Debré University Hospital, Paris, France. ${ }^{14}$ Internal Medicine, Casablanca University Hospital, Casablanca, Morocco. ${ }^{15}$ Clinical Research, Bicêtre University Hospital, Le Kremlin Bicêtre, France.

Published: 5 December 2013

doi:10.1186/1546-0096-11-S2-P309

Cite this article as: Koné-Paut et al:: PReS-FINAL-2319: PED-BD cohort 2013: expert consensus classification gives higher sensitivity than the international study group criteria to define Behcet's disease in children. Pediatric Rheumatology 2013 11(Suppl 2):P309.

\section{Submit your next manuscript to BioMed Central} and take full advantage of:

- Convenient online submission

- Thorough peer review

- No space constraints or color figure charges

- Immediate publication on acceptance

- Inclusion in PubMed, CAS, Scopus and Google Scholar

- Research which is freely available for redistribution

Submit your manuscript at www.biomedcentral.com/submit
Ciomed Central 